\title{
A Boiling-Water-Stable, Tunable White-Emitting Metal-Organic Framework from Soft-Imprint Synthesis
}

\author{
Jun He, ${ }^{*[a]}$ Jian Huang, ${ }^{[\mathrm{a}]}$ Yonghe $\mathrm{He}^{[\mathrm{a}]}$ Peng Cao, ${ }^{[\mathrm{a}]}$ Matthias Zeller, ${ }^{[\mathrm{b}]}$ Allen D. Hunter, ${ }^{[\mathrm{b}]}$ and \\ Zhengtao $\mathrm{Xu}^{*[\mathrm{c}]}$
}

\begin{abstract}
A new avenue for making porous frameworks has been developed by borrowing an idea from molecularly imprinted polymers (MIPs). In lieu of the small molecules commonly used as templates in MIPs, soft metal components, such as Cul, are used to orient the molecular linker and to leverage the formation of the network. Specifically, a linear dicarboxylate linker with thioether side groups reacted simultaneously with $\mathrm{Ln}^{3+}$ ions and Cul, leading to a bimetallic net featuring strong, chemically hard $\mathrm{Eu}^{3+}$-carboxylate links, as well as soft, thioetherbound $\mathrm{Cu}_{2} \mathrm{I}_{2}$ clusters. The Cul block imparts water stability to the host; with the tunable luminescence from the lanthanide ions, this creates the first white-emitting MOF that is stable in boiling water. The $\mathrm{Cu}_{2} \mathrm{I}_{2}$ block also readily reacts with $\mathrm{H}_{2} \mathrm{~S}$, and enables sensitive colorimetric detection while the host net remains intact.
\end{abstract}

Templating is a tried-and-true strategy of wide use in materials synthesis, with examples including molecularly imprinted polymers $(\mathrm{MIP})^{[1]}$ and the organic template-directed syntheses of zeolitic materials. ${ }^{[2]}$ In the former, the small-molecule template is intended as a mold to orient the functional groups on the growing polymer, in order to impart enzyme-like recognition properties to the (subsequently evacuated) polymer host; the supple nature of the polymer backbone could, however, compromise the structural memory. By comparison, in the very rigid zeolitic grid, the pore size and geometry templated by the organic molecule are often well retained, even when the organic templates have been burned away.

[a] Prof. J. He, J. Huang, Y. He, P. Cao

School of Chemical Engineering and Light Industry

Guangdong University of Technology

Guangzhou 510006, Guangdong (P.R. China)

E-mail:junhe@gdut.edu.cn

[b] Dr. M. Zeller, Dr. A. D. Hunter

Department of Chemistry, Youngstown State University

One University Plaza, Youngstown, $\mathrm{OH} 44555$ (USA)

[c] Prof. Z. Xu

Department of Biology and Chemistry, City University of Hong Kong 83 Tat Chee Avenue, Kowloon, Hong Kong (P.R. China)

E-mail: zhengtao@cityu.edu.hk

$\square$ Supporting information for this article is available on the WWW under http://dx.doi.org/10.1002/chem.201504941. CCDC 1421986 and 1422000 contain the supplementary crystallographic data for this paper. These data are provided free of charge by The Cambridge Crystallographic Data Centre.
The common, long-standing practice of templating, is, however, conspicuously under-explored in the assembly of metalorganic frameworks, ${ }_{1}^{[3]}$ in which the use of rigid, open-shaped molecular linkers, in combination with metal cluster nodes, ${ }^{[4]}$ serves to impose the porous characters of the resultant solid grid. In other words, the use of templates to purposely direct structure and create cavities appears to be unnecessary, and is therefore often not factored into the synthetic design of MOF materials. Among the scarce examples of deliberately using templates to influence the framework formation, the template acts either as an auxiliary ligand bound to the metal center ${ }^{[5]}$ or simply as a space holder without well-defined contacts with the framework atoms. Instead of closely molding the shape and function of the cavities, as in MIPs, templates generally do not leave distinct imprints on the MOF grid. ${ }^{[6]}$

We therefore suspect that there is room for further deploying the templating strategy in the synthesis of metal-organic frameworks. In this work, we envision the template in the form of secondary, soft metal ions that stand apart from the primary (often hard) metal ions incorporated within the host net. This thought traces back to reported works on hard and soft linkers for MOF construction, as exemplified by the carboxylate-sulfur combination. ${ }^{[7]}$ Previously, we reported the simultaneous reaction of a bifunctional molecule with two distinct metal species: one chemically hard metal (e.g., $\mathrm{Eu}^{3+}$ ) for interconnecting the carboxyl ends; the other, chemically soft (e.g., $\mathrm{AgCl}$ ), intended for the thioether units. $^{[8]}$ The soft metal, being bound by the weaker thioether donors, plays a lesser role in determining the structural integrity of the Eu'l'-carboxylate host net. For example, the soft metal can be dislodged by treatment with $\mathrm{H}_{2} \mathrm{~S}$ to form $\mathrm{Ag}_{2} \mathrm{~S}$ particles, without collapsing the primary metal-carboxylate scaffold. In general, such treatment represents a unique method for imbedding semiconducting metal chalcogenide nanostructures within well-defined MOF hosts, a method that also chimes with the popular practice of postsynthetic modification (PSM). ${ }^{[8,9]}$

We describe herein an exercise in MOF synthesis that further highlights the advantages of this strategy of soft imprinting. Unlike our previous work ${ }^{[8]}$ in which the soft metal did not affect the connectivity of the metal-carboxylate host net, the soft part (i.e., Cul) in the present case acts as a structural modulator that opens up the framework-a role that more closely connects to the templating strategy in molecularly imprinted polymers. The experiment involved the reaction of the thioether-carboxylate ligand $\mathrm{H}_{2} \mathrm{~L}$ (see the Supporting Information for details of the synthesis) with lanthanide ions (e.g., $\mathrm{Eu}^{3+}$ ) while 


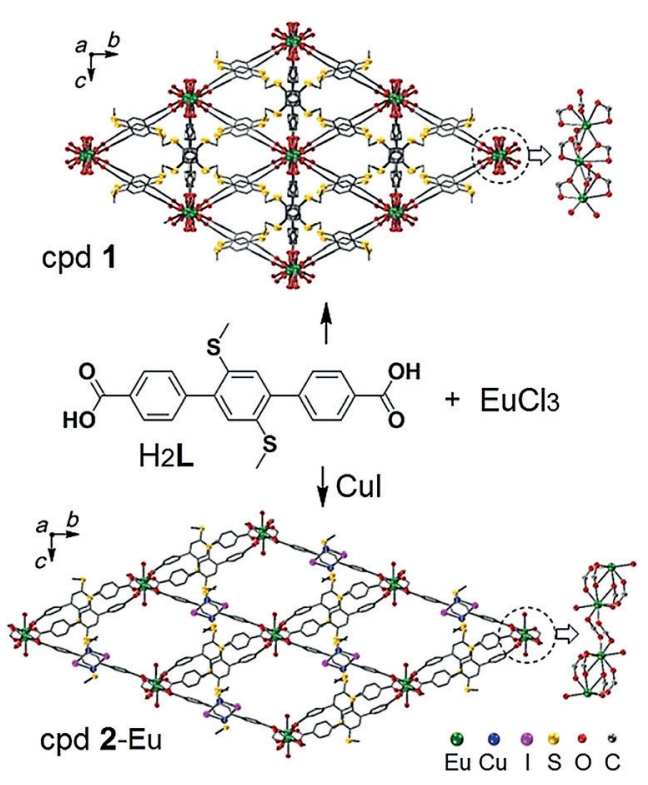

Figure 1. Synthetic Scheme and crystal structures of framework compounds 1 (top panel) and 2-Eu (bottom panel). Disordering of atom positions is omitted in 1 for clarity.

testing the structural impact of Cul as the secondary, soft component (Figure 1). On the practical side, the MOF product thus discovered features a unique combination of substantial porosity, tunable luminescence, and remarkable stability-for example, the structure is stable even in boiling water. Moreover, the imbedded $\mathrm{Cul}$ clusters react readily with $\mathrm{H}_{2} \mathrm{~S}$ without degrading the host lattice, highlighting its template-like, deliverable character.

The presence of Cul crucially impacts the structures of the resultant networks. Without $\mathrm{Cul}$, the solvothermal synthesis using $\mathrm{H}_{2} \mathrm{~L}$ and $\mathrm{EuCl}_{3} \cdot 6 \mathrm{H}_{2} \mathrm{O}$ (in 1:1 water/acetonitrile at $140^{\circ} \mathrm{C}$; see the Supporting Information for details) yielded a closepacked, nonporous single-crystalline solid (denoted as compound 1) with a composition $\left\{\mathrm{Eu}(\mathrm{L})_{1.5}\right\}$, with $\mathrm{Eu}^{3+}$-carboxylate chains integrated into a 3D net by the aromatic bridges of the L molecules (Figure 1, top). ${ }^{[10]}$ Besides its nonporous character, the crystals of $\mathbf{1}$ are nearly non-emissive under UV radiation, presumably due to the intermolecular luminescence quenching across the densely packed $\mathbf{L}$ molecules.

By contrast, when Cul was included in the above solvothermal procedure, an open, porous framework was produced (denoted as 2-Eu), with the composition $\left\{\mathrm{Eu}(\mathrm{L})_{1.5}(\mathrm{Cul})\left(\mathrm{H}_{2} \mathrm{O}\right)\right\}$ for the main grid resolved by single-crystal diffraction. ${ }^{[11]}$ Compared with the light yellow, non-emissive crystals of 1, the crystals of 2-Eu are colorless and exhibit distinct red photoluminescence (i.e., from the $\mathrm{Eu}^{3+}$ center; see also Figure S1 in the Supporting Information for photographs and emission spectra). Besides the rod-like $\mathrm{Eu}^{3+}$-carboxylate domains, which were similarly formed in compound 1, the Cul component in 2-Eu coordinates to the sulfur atoms of $\mathbf{L}$, orientating the $\mathbf{L}$ molecules and Eu centers to form an open framework.

The parallelogrammatic $\mathrm{Cu}_{2} \mathrm{I}_{2}$ dimer is centrosymmetric, with the two $\mathrm{Cu}^{\prime}$ centers adopting identical bonding environments (bond lengths: $\mathrm{Cu}-\mathrm{l}$ : 2.654 and $2.646 \AA$; Cu...Cu: $2.807 \AA$; Figure 2). Besides the two iodide ions, each $\mathrm{Cu}^{\prime}$ center is also coordinated by two $\mathrm{S}$ atoms; each $\mathrm{Cu}$ is thus bonded to two $\mathrm{L}$ molecules. Among the two $\mathbf{L}$ molecules, one serves as a linear bridge to link the $\mathrm{Cu}_{2} \mathrm{I}_{2}$ units into a 1D coordination chain, with both $\mathrm{S}$ atoms bonded to the $\mathrm{Cu}^{\prime}$ centers $(\mathrm{Cu}-\mathrm{S}$ distance: $2.363 \AA$ ). The other $\mathrm{L}$ molecule, however, only has one $\mathrm{S}$ atom bonded to the $\mathrm{Cu}_{2} \mathrm{I}_{2}$ unit ( $\mathrm{Cu}-\mathrm{S}$ dis-

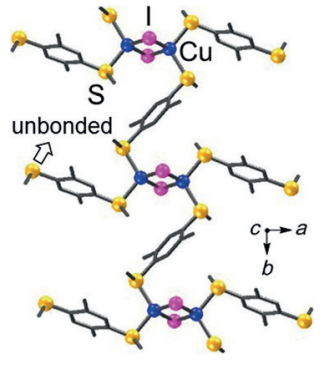

Figure 2. The $\mathrm{Cu}_{2} \mathrm{I}_{2}$-thioether coordination chain in the crystal structure of 2-Eu; only the central benzene rings are shown for the $\mathbf{L}$ molecules. tance: $2.355 \AA$ ) and therefore does not increase the dimensionality of the $\mathrm{Cu}_{2} \mathrm{l}_{2}-\mathrm{L}$ coordination chain, which remains one-dimensional and runs parallel to the Eu-carboxylate rods, along the $c$ axis of the unit cell.

The porosity of 2-Eu was assessed by BET measurement using $\mathrm{N}_{2}$ at $77 \mathrm{~K}$. From the typical type I gas-adsorption isotherms, the corresponding surface area was determined to be $560 \mathrm{~m}^{2} \mathrm{~g}^{-1}$ (Figure 3) and the pore volume $0.304 \mathrm{~cm}^{3} \mathrm{~g}^{-1}$. Analysis from the BET data indicated the pore diameter to be $7.5 \AA$ (see the Supporting Information, Figure S2), being consistent with the single crystal structure.

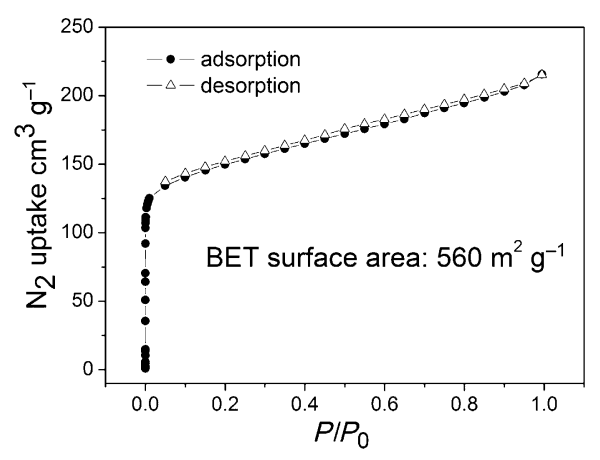

Figure 3. The $\mathrm{N}_{2}$ sorption isotherm at $77 \mathrm{~K}$ for 2 -Eu.

The stability of the 2-Eu solid was highlighted by a series of tests. For example, after being heated at $200^{\circ} \mathrm{C}$ for $4 \mathrm{~h}$ under evacuation by an oil pump, the crystalline order of the host net of 2-Eu remained intact, as indicated by powder X-ray diffraction (PXRD; Figure 4C). The thermal stability was also supported by thermogravimetric analysis (TGA; see the Supporting Information, Figure S3), which indicated minimal weight loss from the host net up to $240^{\circ} \mathrm{C}$. More impressively, even after being boiled in water for $24 \mathrm{~h}$, the solid sample of 2 -Eu continues to exhibit strong and sharp X-ray diffraction peaks, producing a PXRD pattern hardly changed from that of the as-made sample (pattern d of Figure 4). The remarkable water stability of 2-Eu mainly originates from the high valence of the Eu'll ion, whereas the chemically soft $\mathrm{Cu}_{2} \mathrm{I}_{2}$-thioether links, besides strengthening the overall framework, might also help to repel water molecules. ${ }^{[12]}$ 


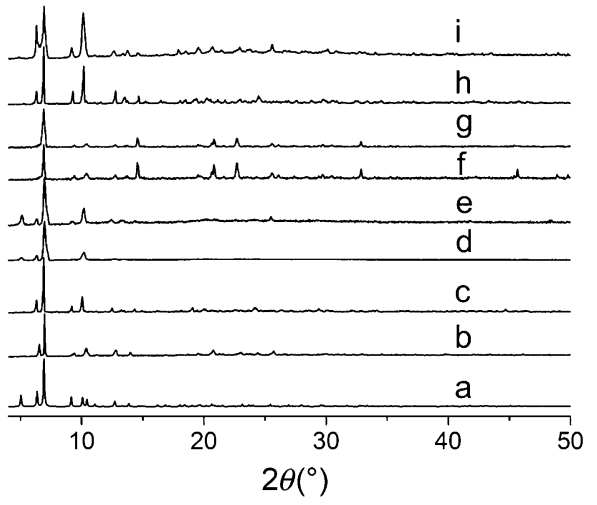

Figure 4. X-ray powder patterns of 2-Eu and analogues: a) Calculated from the single-crystal structure of 2-Eu; b) an as-made sample of 2-Eu; c) sample from (b) after treatment in boiling water for $24 \mathrm{~h}$; d) sample from (b) evacuated by an oil pump at $200^{\circ} \mathrm{C}$ for $4 \mathrm{~h}$; e) sample from (b) treated with $\mathrm{H}_{2} \mathrm{~S}$ for 1 day; $f$ ) an as-made sample of 2-Tb; $g$ ) sample from ( $f$ ) after treatment in boiling water for $24 \mathrm{~h}$; $\mathrm{h}$ ) an as-made sample of $2-\mathrm{Eu} / \mathrm{Tb}$; i) sample from (h) after treatment in boiling water for $24 \mathrm{~h}$

The very similar bonding behaviors of $\mathrm{Eu}^{3+}$ and $\mathrm{Tb}^{3+}$ ions allow both ions to be conveniently mixed together into the host framework. ${ }^{[13]}$ Indeed, $\mathrm{Tb}^{3+}$ readily forms an isostructural net (denoted as 2-Tb) under similar conditions, and bimetallic nets containing evenly mixed $\mathrm{Eu} / \mathrm{Tb}$ ions at variable ratios (i.e., 2-Eu/Tb systems) can be readily accessed by adjusting the metal ratios in the reaction mixture (e.g., Figure $4 \mathrm{~g}-\mathrm{i}$ ). As the red emission from the $\mathrm{Eu}^{3+}$ ions complements the green from $\mathrm{Tb}^{3+}$ (Figure $5 \mathrm{a}$ ), the photoluminescence properties can be systematically tuned by the $\mathrm{Eu} / \mathrm{Tb}$ ratio that is built into the host net (see also Figure $5 \mathrm{~b}$ ). For example, when a 1:18 Eu/Tb mixture was used in the reaction (see the Supporting Information for details), a white-light-emitting framework solid ${ }^{[14]}$ was produced with a CIE coordinate of $(0.31,0.33)$ (Figure $5 \mathrm{c}$ ). The solid product features an Eu/Tb molar ratio of 1:10, and exhibits a fluorescence quantum efficiency of $5.6 \%$ (see Supporting Information for measurement details and Figure $4 \mathrm{~h}$ for PXRD pattern).

Like 2-Eu, the 2-Tb and 2-Eu/Tb crystal samples are highly stable solid-state materials; their crystalline orders remain intact even after being boiled in water for $24 \mathrm{~h}$, as indicated by PXRD (Figure $4 \mathrm{~g}$, i). Moreover, no apparent change in the color quality of the photoluminescence was observed after the boiling water treatment, allowing, for the first time, the attainment of a porous white-light emitting solid framework that is stable in boiling water. To explore further applications, the whitelight-emitting solid 2-Eu/Tb, as well as analogues of $\mathbf{2}$ at different $\mathrm{Eu} / \mathrm{Tb}$ ratios, can be easily coated (by means of slurrying with ethanol; see the Supporting Information for details) on a commercial UV LED, to provide lighting devices with various color qualities (Figure 5 b). Consistent with robust water stability of the coating materials, these lighting devices are especially durable: for example, even after being exposed in the humid climate of Guangzhou for over half a year, no visible change in the emission colors was observed.

Besides stability and luminescence, the Cul component bestows unique advantages on the host net of 2-Eu. Specifically,
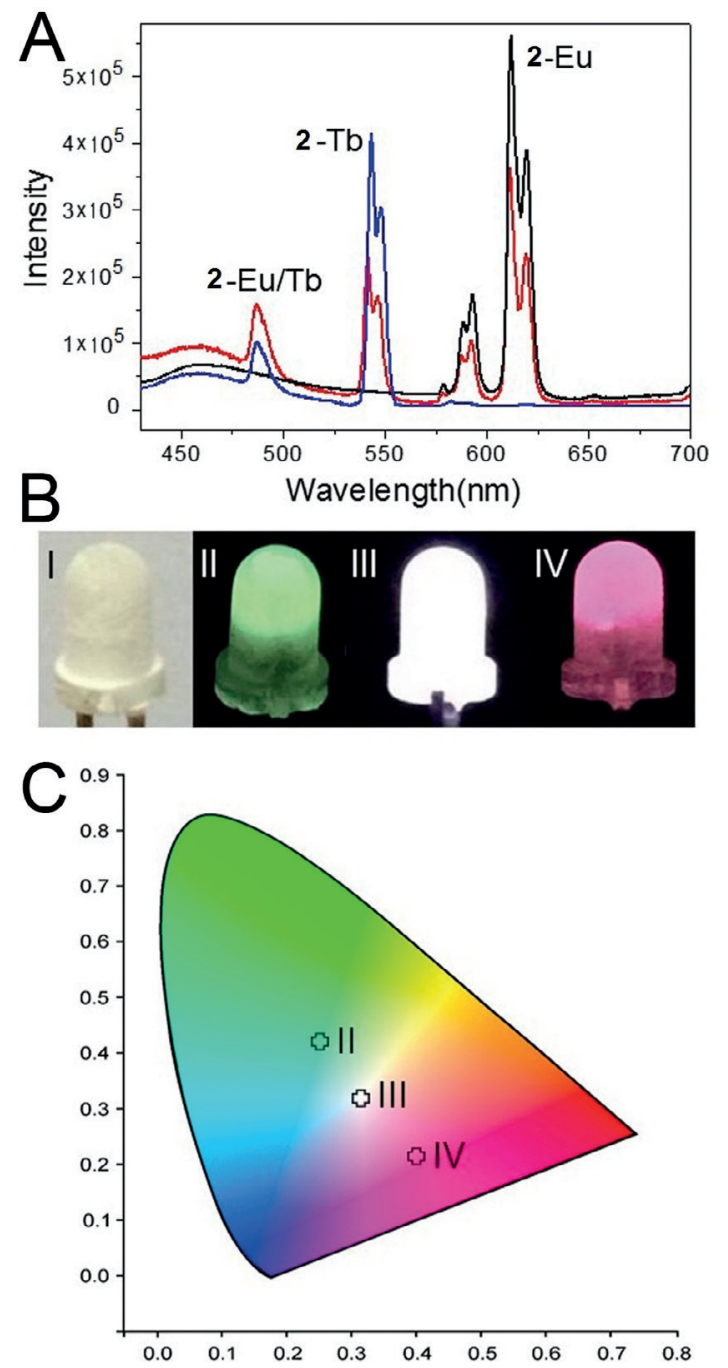

Figure 5. a) Room temperature emission spectra of 1, 2-Eu, 2-Tb, and 2-Eu/ $\mathrm{Tb}$ in the solid state $\left.\left(\lambda_{\mathrm{ex}}=390 \mathrm{~nm}\right) ; \mathrm{b}\right)$ photographs of LEDs: (I) a $3 \mathrm{~mm}$ UV LED coated with 2-Eu/Tb (not turned on); (II), (III), and (IV) are coated by 2Tb, 2-Eu/Tb and 2-Eu, respectively (turned on); c) CIE 1931 chromaticity diagram and the positions (marked by crosses) for the emissions of 2-Eu (II), 2$\mathrm{Tb}$ (III), and 2-Eu/Tb (IV); corresponding coordinates: $(0.26,0.42),(0.31,0.33)$, $(0.41,0.22)$.

the chemically soft $\mathrm{Cu}_{2} \mathrm{I}_{2}$ unit is coordinated by the soft and relatively weak donors of thioether groups. On the one hand, such soft-soft (hydrophobic) coordination repels water incursion and improves stability in aqueous conditions; on the other, the $\mathrm{Cu}_{2} \mathrm{I}_{2}$ clusters remain susceptible to reactions with guests of strong donors, such as $\mathrm{H}_{2} \mathrm{~S}$ and thiols. In addition, the well-defined porosity and large surface area of the host net renders the Cul components readily accessible to incoming guest molecules. To deliver the $\mathrm{Cu}_{2} \mathrm{l}_{2}$ cluster as a functional payload, we studied the interaction between 2-Eu crystals and $\mathrm{H}_{2} \mathrm{~S}$, and examined its potential utility in sensing and detection applications.

The 2-Eu crystals respond to $\mathrm{H}_{2} \mathrm{~S}$ with high sensitivity (see the Supporting Information, Figure S4). For example, at room temperature, a $20 \mathrm{ppm}$ aqueous solution of $\mathrm{H}_{2} \mathrm{~S}$ quenches the red fluorescence of 2-Eu within half an hour. At $80^{\circ} \mathrm{C}$, even at 


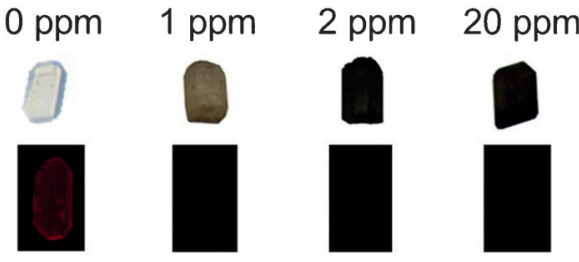

Figure 6. Photographs of the 2-Eu single crystal after being soaked in solutions with $\mathrm{H}_{2} \mathrm{~S}$ at various concentrations for $2 \mathrm{~h}$ at $80^{\circ} \mathrm{C}$ under natural light (top row) and under $365 \mathrm{~nm}$ UV radiation (bottom row).

$1.0 \mathrm{ppm}$ of $\mathrm{H}_{2} \mathrm{~S}$, the emission from the crystal of 2-Eu was largely quenched within $2 \mathrm{~h}$. More conveniently, as shown in Figure 6 , the originally colorless crystals of 2-Eu became significantly darker (from brown to black) in the process, indicating a readily usable colorimetric sensing capability. Taken together, these sensing tests demonstrate the framework systems of 2$\mathrm{Eu}$ to be especially versatile for monitoring $\mathrm{H}_{2} \mathrm{~S}$ in water/airbased biological, industrial, and environmental assays. ${ }^{[15]}$ The readily available single crystals, as well as the low-cost fabrication of the lighting device, make for convenient disposable applications.

The network system of 2-Eu is also found to be remarkably stable to $\mathrm{H}_{2} \mathrm{~S}$. Even after being immersed in pure $\mathrm{H}_{2} \mathrm{~S}$ (1.0 atm) for $24 \mathrm{~h}$, the crystals of 2 -Eu retained their original crystalline order, as shown by the sharp and strong peaks in the PXRD (Figure $4 \mathrm{e}$ ); as it were, the host net maintains its structure, in spite of the drastic reaction between the Cul component and $\mathrm{H}_{2} \mathrm{~S}$ guests. Elemental analyses (see the Supporting Information for data) also indicated an increase in the $S$ content; the composition found for the $\mathrm{H}_{2} \mathrm{~S}$-treated 2-Eu sample was consistent with $\left\{\mathrm{Eu}_{2}(\mathrm{~L})_{3}(\mathrm{Cul})_{2}\left(\mathrm{H}_{2} \mathrm{~S}\right)_{2}\right\}$. X-ray photoelectron spectroscopy (XPS; see the Supporting Information, Figure S5) revealed a distinct shift of, for example, the $\mathrm{Cu} 2 \mathrm{p}_{3 / 2}$ peak toward lower energy after the $\mathrm{H}_{2} \mathrm{~S}$ treatment (from 933.1 to $932.8 \mathrm{eV}$ ), which is consistent with the binding of $\mathrm{H}_{2} \mathrm{~S}$ as a strong electron donor that consequently decreases the binding energies of the metal center. Further study is ongoing to fully vacate the sulfur pocket templated by the Cul cluster for specific binding tests, in order to further unveil the soft-imprinting character of this strategy for MOF synthesis.

\section{Acknowledgements}

This work is supported by National Natural Science Foundation of China (21471037, 21201042), enhancement program (Yq2013058), City University of Hong Kong (Project no. 9667092) and the Research Grants Council of HKSAR [GRF 103413]. The diffractometer was funded by NSF Grant 0087210, by Ohio Board of Regents Grant CAP-491, and by Youngstown State University.

Keywords: host-guest systems $\cdot$ imprinting $\cdot$ metal-organic frameworks $\cdot$ sensors $\cdot$ template synthesis
[1] a) J. L. Bowen, P. Manesiotis, C. J. Allender, Mol. Imprinting 2013, 1, 35 40 ; b) C. Alexander, S. Andersson Hakan, I. Andersson Lars, J. Ansell Richard, N. Kirsch, A. Nicholls lan, J. O'Mahony, J. Whitcombe Michael, J. Mol. Recognit. 2006, 19, 106-180; c) G. Wulff, Chem. Rev. 2002, 102, 1 27; d) G. Wulff, A. Sarhan, Angew. Chem. Int. Ed. Engl. 1972, 11, 341; Angew. Chem. 1972, 84, 364.

[2] a) Q. Lin, X. Bu, C. Mao, X. Zhao, K. Sasan, P. Feng, J. Am. Chem. Soc. 2015, 137, 6184-6187; b) H.-Y. Lin, C.-Y. Chin, H.-L. Huang, W.-Y. Huang, M.-J. Sie, L.-H. Huang, Y.-H. Lee, C.-H. Lin, K.-H. Lii, X. Bu, S.-L. Wang, Science 2013, 339, 811-813; c) R. Simancas, D. Dari, N. Velamazan, M. T. Navarro, A. Cantin, J. L. Jorda, G. Sastre, A. Corma, F. Rey, Science 2010, 330, 1219-1222; d) A. Jackowski, S. I. Zones, S.-J. Hwang, A. W. Burton, J. Am. Chem. Soc. 2009, 131, 1092-1100; e) A. Corma, M. J. Diaz-Cabanas, J. L. Jorda, F. Rey, G. Sastre, K. G. Strohmaier, J. Am. Chem. Soc. 2008, 130, 16482-16483; f) P. Feng, X. Bu, N. Zheng, Acc. Chem. Res. 2005, 38, 293-303; g) S. Ekambaram, S. C. Sevov, Angew. Chem. Int. Ed. 1999, 38, 372-375; h) D. J. Chesnut, D. Hagrman, P. J. Zapf, R. P. Hammond, R. LaDuca, R. C. Haushalter, J. Zubieta, Coord. Chem. Rev. 1999, $190-192,737-769$.

[3] a) Y.-B. Zhang, H. Furukawa, N. Ko, W. Nie, H. J. Park, S. Okajima, K. E. Cordova, H. Deng, J. Kim, O. M. Yaghi, J. Am. Chem. Soc. 2015, 137, 2641-2650; b) K. Manna, T. Zhang, F. X. Greene, W. Lin, J. Am. Chem. Soc. 2015, 137, 2665-2673; c) M. G. Campbell, D. Sheberla, S. F. Liu, T. M. Swager, M. Dinca, Angew. Chem. Int. Ed. 2015, 54, 4349-4352; Angew. Chem. 2015, 127, 4423-4426; d) B. Li, M. Chrzanowski, Y. Zhang, S. Ma, Coord. Chem. Rev. 2016, 307, 106-129; e) Y. Cui, F. Zhu, B. Chen, G. Qian, Chem. Commun. 2015, 51, 7420-7431; f) J. Cui, Z. Xu, Chem Commun. 2014, 50, 3986-3988; g) Z. Xu, Coord. Chem. Rev. 2006, 250, 2745-2757; h) C.-D. Wu, A. Hu, L. Zhang, W. Lin, J. Am. Chem. Soc. 2005, 127, 8940-8941; i) O. M. Yaghi, G. M. Li, H. L. Li, Nature 1995, 378, $703-706$; j) G. B. Gardner, D. Venkataraman, J. S. Moore, S. Lee, Nature 1995, 374, 792-795; k) B. F. Hoskins, R. Robson, J. Am. Chem. Soc. 1989 $111,5962-5964$.

[4] N.W. Ockwig, O. Delgado-Friedrichs, M. O'Keeffe, O. M. Yaghi, Acc. Chem. Res. 2005, 38, 176-182.

[5] D. Bradshaw, T. J. Prior, E. J. Cussen, J. B. Claridge, M. J. Rosseinsky, J. Am. Chem. Soc. 2004, 126, 6106-6114.

[6] a) A. C. Tella, O. A. Ameen, P. A. Ajibade, L. O. Alimi, J. Porous Mater 2015, 22, 1599-1605; b) T. Friščić, D. G. Reid, I. Halasz, R. S. Stein, R. E. Dinnebier, M. J. Duer, Angew. Chem. Int. Ed. 2010, 49, 712-715; Angew. Chem. 2010, 122, 724-727.

[7] a) B. Gui, K.-K. Yee, Y.-L. Wong, S.-M. Yiu, M. Zeller, C. Wang, Z. Xu, Chem Commun. 2015, 51, 6917-6920; b) M. Zha, J. Liu, Y.-L. Wong, Z. Xu, J. Mater. Chem. A 2015, 3, 3928-3934; c) H. Fei, S. M. Cohen, J. Am. Chem. Soc. 2015, 137, 2191-2194; d) L. Sun, C. H. Hendon, M. A. Minier, A. Walsh, M. Dinca, J. Am. Chem. Soc. 2015, 137, 6164-6167; e) Z. Xu, Metal-organic Frameworks: Semiconducting Frameworks, John Wiley \& Sons, Ltd, Chichester, 2014; f) J. Cui, Y.-L. Wong, M. Zeller, A. D. Hunter, Z. Xu, Angew. Chem. Int. Ed. 2014, 53, 14438-14442; Angew. Chem. 2014, 126, 14666-14670; g) L. Sun, T. Miyakai, S. Seki, M. Dincă, J. Am. Chem. Soc. 2013, 135, 8185-8188; h) S. Pullen, H. Fei, A. Orthaber, S. M. Cohen, S. Ott, J. Am. Chem. Soc. 2013, 135, 16997-17003; i) K.-K. Yee, N. Reimer, J. Liu, S.-Y. Cheng, S.-M. Yiu, J. Weber, N. Stock, Z. Xu, J. Am Chem. Soc. 2013, 135, 7795-7798; j) J. He, M. Zha, J. Cui, M. Zeller, A. D. Hunter, S.-M. Yiu, S.-T. Lee, Z. Xu, J. Am. Chem. Soc. 2013, 135, $7807-$ 7810 ; k) A. D. Burrows, C. G. Frost, M. F. Mahon, C. Richardson, Chem. Commun. 2009, 4218-4220; I) J. He, C. Yang, Z. Xu, M. Zeller, A. D. Hunter, J. Lin, J. Solid State Chem. 2009, 182, 1821 -1826; m) X.-P. Zhou, Z. Xu, M. Zeller, A. D. Hunter, S. S.-Y. Chui, C.-M. Che, Inorg. Chem. 2008 , 47, 7459-7461.

[8] X.-P. Zhou, Z. Xu, M. Zeller, A. D. Hunter, S. S.-Y. Chui, C.-M. Che, J. Lin, Inorg. Chem. 2010, 49, 7629-7631.

[9] a) W. M. Bloch, A. Burgun, C. J. Coghlan, R. Lee, M. L. Coote, C. J. Doonan, C. J. Sumby, Nat. Chem. 2014, 6, 906-912; b) Z. Wang, S. M. Cohen, Chem. Soc. Rev. 2009, 38, 1315-1329; c) Z. Xu, S. Lee, Y.-H. Kiang, A. B. Mallik, N. Tsomaia, K. T. Mueller, Adv. Mater. 2001, 13, 637641.

[10] Crystal data for 1: $\mathrm{EuC}_{33} \mathrm{H}_{25} \mathrm{O}_{6} \mathrm{~S}_{3} ; M_{\mathrm{r}}=765.67 ;$ Fddd; $a=7.011(2), b=$ 34.41(1), $c=55.94(2) \AA ; \alpha=\beta=\gamma=90^{\circ} ; V=13494$ (7) $\AA^{3} ; Z=16 ; \rho=$ $1.508 \mathrm{~g} \mathrm{~cm}^{-3} ; \quad \mathrm{GOF}=1.078 ; \quad R_{1}=0.0452 ; \quad w R_{2}=0.1246 \quad[I>2 \sigma(l)]$. CCDC 1421986 contains the crystallographic data for 1 . 
[11] Crystal data for 2-Eu: EuCulC ${ }_{33} \mathrm{H}_{26} \mathrm{O}_{7} \mathrm{~S}_{2} ; M_{\mathrm{r}}=973.12 ; P \overline{1} ; a=9.116(3), b=$ $15.128(4), c=18.517(5) \AA ; \alpha=102.480(7), \beta=99.371(9), \gamma=106.819(7)^{\circ}$; $V=2316(1) \AA^{3} ; Z=2 ; \rho=1.395 \mathrm{~g} \mathrm{~cm}^{-3} ; \mathrm{GOF}=1.031 ; R_{1}=0.0874 ; w R_{2}=$ $0.2115[I>2 \sigma(I)]$. CCDC 1422000 contains the crystallographic data for 2-Eu.

[12] a) For a recent Eu-based water-stable MOF, see: D.-X. Xue, Y. Belmabkhout, O. Shekhah, H. Jiang, K. Adil, A. J. Cairns, M. Eddaoudi, J. Am. Chem. Soc. 2015, 137, 5034-5040; b) for a review on water-stable MOFs, see: N. C. Burtch, H. Jasuja, K. S. Walton, Chem. Rev. 2014, 114, 10575-10612.

[13] X. Rao, Q. Huang, X. Yang, Y. Cui, Y. Yang, C. Wu, B. Chen, G. Qian, J. Mater. Chem. 2012, 22, 3210-3214.

[14] a) W. Liu, Y. Fang, G. Z. Wei, S. J. Teat, K. Xiong, Z. Hu, W. P. Lustig, J. Li, J. Am. Chem. Soc. 2015, 137, $9400-9408$; b) J. Chen, Q. Zhang, Z.-F. Liu, S.H. Wang, Y. Xiao, R. Li, J.-G. Xu, Y.-P. Zhao, F.-K. Zheng, G.-C. Guo, Dalton Trans. 2015, 44, 10089-10096; C) L. Chen, C. Yan, M. Pan, Y.-Z. Fan, L.-Y. Zhang, S.-Y. Yin, Y.-J. Hou, K. Wu, J.-J. Jiang, C.-Y. Su, New J. Chem. 2015 39, 5287-5292; d) Y. Cui, T. Song, J. Yu, Y. Yang, Z. Wang, G. Qian, Adv. Funct. Mater. 2015, 25, 4796-4802; e) W. Xie, S.-R. Zhang, D.-Y. Du, J.-S Qin, S.-J. Bao, J. Li, Z.-M. Su, W.-W. He, Q. Fu, Y.-Q. Lan, Inorg. Chem. 2015, 54, 3290-3296; f) Y. Zhou, B. Yan, Nanoscale 2015, 7, 4063-4069; g) S. Zou, Q. Li, S. Du, RSC Adv. 2015, 5, 34936-34941; h) J. He, M. Zeller, A. D. Hunter, Z. Xu, J. Am. Chem. Soc. 2012, 134, 1553-1559; i) W. Ki, J. Li, J. Am. Chem. Soc. 2008, 130, 8114-8115.

[15] a) S. K. Bae, C. H. Heo, D. J. Choi, D. Sen, E.-H. Joe, B. R. Cho, H. M. Kim, J. Am. Chem. Soc. 2013, 135, 9915-9923; b) N. Kumar, V. Bhalla, M. Kumar, Coord. Chem. Rev. 2013, 257, 2335-2347; c) G.-J. Mao, T.-T. Wei, X.-X. Wang, S.-y. Huan, D.-Q. Lu, J. Zhang, X.-B. Zhang, W. Tan, G.-L. Shen, R.-Q. Yu, Anal. Chem. 2013, 85, 7875-7881; d) L. A. Montoya, T. F. Pearce, R. J. Hansen, L. N. Zakharov, M. D. Pluth, J. Org. Chem. 2013, 78, 6550-6557; e) H. Zhang, P. Wang, G. Chen, H.-Y. Cheung, H. Sun, Tetrahedron Lett. 2013, 54, 4826-4829; f) F. Zheng, M. Wen, F. Zeng, S. Wu, Polymer 2013, 54, 5691-5697; g) L. A. Montoya, M. D. Pluth, Chem. Commun. 2012, 48, 4767-4769; h) V. S. Lin, C. J. Chang, Curr. Opin Chem. Biol. 2012, 16, 595-601; i) H. Peng, W. Chen, Y. Cheng, L. Hakuna, R. Strongin, B. Wang, Sensors 2012, 12, 15907-15946; j) A. R. Lippert, E. J. New, C. J. Chang, J. Am. Chem. Soc. 2011, 133, 10078-10080.

Received: December 9, 2015

Published online on January 8, 2016 